\title{
RAZA, ESCRITURA Y PRENSA: EL CASO DEL PERIÓDICO O MESTRE BARBEIRO (PORTO ALEGRE, 1835)
}

\author{
María Laura Romano \\ Universidad de Buenos Aires \\ Buenos Aires, Argentina \\ goriotlr@hotmail.com
}

RESUMEN / ABSTRACT

El artículo aborda un periódico antiliberal titulado $O$ Mestre Barbeiro, que fue publicado en Porto Alegre en 1835 durante los meses previos al desencadenamiento de la Revolução Farroupilha. La propuesta es analizar dos aspectos: por un lado, la delegación ficticia y farsesca de la escritura en un barbero liberal y la pertinencia de los trazos identitarios de esa figura -se deduce que el mestre barbeiro era negro- en un contexto en el que se debatía el acceso a la ciudadanía de los sectores subalternos (incluidos los esclavos y los ex-esclavos). Por otro lado, indagaremos los mecanismos empleados para (des)componer el discurso del imaginario redactor, ubicado en las antípodas ideológicas del verdadero autor de la gaceta, a través de una serie acumulativa de cortes y agregados que redundaban en una tergiversación del ideario del liberalismo.

Palabras Clave: O Mestre Barbeiro, prensa y literatura, crítica literaria, Brasil, siglo XIX.

Race, writing and press: the CaSe of the newspaper O Mestre Barbeiro (PoRTO ALEGRE, 1835)

The article addresses an anti-liberal newspaper, $O$ Mestre Barbeiro, published in Porto Alegre in 1835 during the months prior to the outbreak of the Revolução Farroupilha. The proposal is to analyze two aspects: on the one hand, the farcical delegation of the writing in the figure of a barber and the pertinence of the identity traits of that figure-it is deduced that the mestre barbeiro was black-in a context in which the access to citizenship of the subaltern sectors was being questioned (including the slaves and ex-slaves). On the other hand, the mechanisms used to (de)compose the discourse of the imaginary writer, located in the ideological antipodes of the true author of the journal, through a cumulative series of cuts and additions that resulted in a distortion of his senses. 
KEYWORDS: O Mestre Barbeiro, press and literature, literary criticism, Brazil, 19th century.

Recepción: 20/09/2018

Aprobación: 24/07/2019

\section{VENTRILOQUÍA PERIODÍSTICA}

El 19 de septiembre de 1835, en las afueras de Porto Alegre, dieciséis hombres de caballería de la Guarda Nacional se agazapaban en la oscuridad de la noche intentando descubrir el campamento del ejército enemigo que, según la noticia que había circulado en horas de la tarde, se preparaba para invadir la ciudad. Un grupo de centinelas, que custodiaban los alrededores del vivaque, los divisaron y dieron la voz de alerta. A un primer momento de confusión, entre disparos de pistolas y relinchos de caballos, siguió el ataque de los centinelas, que embistieron con sus lanzas a los guardias nacionales: entre las bajas producidas por la escaramuza, se encontraba el teniente Antônio José da Silva Monteiro, redactor de un minúsculo periódico - pequeño como un librito de bolsillo- titulado $O$ Mestre Barbeiro, que había salido a la luz en enero de 1835. El episodio selló los vínculos de esta publicación con el desenvolvimiento de un conflicto que mantendría convulsionada a Rio Grande do Sul durante diez años, la Revolução Farroupilha, en la cual se enfrentaron las fuerzas imperiales con el sector más exaltado de la parcialidad liberal de la provincia brasileña ${ }^{1}$.

1 Los estudios dedicados al conflicto son profusos, por lo que solo esbozaremos un marco comprensivo sobre el cual suele haber consenso en la bibliografía especializada (Pesavento 1985; Flores 1985; Kühn 2002, Alves 2004). Vista desde la historia de la formación del Estado brasileño, la Revolução Farroupilha tuvo dos resortes desencadenantes. En primer lugar, la elite política heredera de la Independencia, que asumió el rol de trazar el armazón jurídico-administrativo del Brasil pos-colonial, representaba los intereses del latifundio cafetero y azucarero, por lo que sus acciones tendían a velar por la inserción del país en el comercio internacional como exportador de materias primas. Esta orientación causaba constantes fricciones con los terratenientes de Rio Grande do Sul en la medida en que su producción (charque fundamentalmente) estaba destinada al mercado interno. Por otro lado, aunque de manera confluyente con lo dicho anteriormente, la inconformidad de los senhores da terra riograndenses se dirigía contra la centralización política y administrativa que las elites del centro del país querían imponer sobre las provincias. Como señalamos, la bibliografía sobre el conflicto es cuantiosa, lo que ha generado interesantes trabajos de historiografía sobre la historiografía. Estos guían al lector a partir de propuestas de sistematización de las distintas orientaciones interpretativas. Véanse especialmente Gutfreind 1992 y Nedel 2005, 2004. 
En el marco de la "guerra de papeles" que, para la época, sacudía el incipiente espacio público de Porto Alegre, el periódico O Recopilador Liberal le dedicó a Silva Monteiro una necrológica vituperante: "Secretário y Agente do Coronel e Major da Legião, agitador de novidades, e Redactor [de] papeluxos que só servião para descompor, intrigar, insultar, e levar ao seio das familias as frases mais indecentes, e deshonestas" $(308)^{2}$. Estas pocas líneas, además de constituir un estimable testimonio de la valoración que los contemporáneos hacían de sus periódicos, resultan muy valiosas debido a la casi total ausencia de información sobre la vida de Silva Monteiro. A contrapelo de ese vacío, en las minúsculas piezas de escritura, retazos de documentos, apenas rastros que lo sobrevivieron, pueden encontrarse elementos interesantes que permiten proponer perspectivas iluminadoras acerca de su perfil letrado y de su particular estilo de escritura. Por ejemplo, Tancredo Fernandes de Mello, en su opúsculo sobre los primeros periódicos de Rio Grande do Sul, aporta un dato sugestivo acerca del escritor, que resulta coherente con el rol de secretario que se le adjudica en el obituario de $O$ Recopilador Liberal. El militar e historiador gaúcho señala que el redactor de $O$ Mestre Barbeiro era funcionario de la Câmara Municipal de Porto Alegre, en la que se desempeñaba como escrivão, esto es, oficiaba de escribiente de ese órgano realizando múltiples tareas, todas ellas relativas al intricado tejido de escrituras administrativas. Si bien no se trataba de un cargo camarário (como el de juez, veedor y procurador), que eran desempeñados habitualmente por los hombres más prestigiosos de la ciudad, su pertenencia a un órgano del tradicional aparato burocrático portugués resultaba acorde con ciertos contenidos ideológicos de su periódico. Estos elementos reunidos, a los que puede sumarse su participación en la Guarda Nacional (cuerpo al que solo podían ingresar los ciudadanos que gozaban de determinada renta), permiten construir una semblanza de Silva Monteiro que lo aproxima al lusófilo Partido Restaurador, la parcialidad más reaccionaria del espectro político del Imperio brasileño de aquellos años. Precisamente, en los ámbitos urbanos, sectores ligados a la burocracia componían uno de los segmentos sociales que conformaban el mosaico de fuerzas políticas confluyentes en el restauracionismo (Morel, "Restaurar" 429). Se trataba de sectores que

2 En todas las citas de los periódicos, hemos conservado su ortografía, su puntuación y respetado las marcas de énfasis que pertenecen a la fuente. Citamos las publicaciones indicando entre paréntesis el número dentro de la serie y luego la paginación original (si la tiene). 
deseaban restablecer sus antiguas posiciones de privilegio, alteradas por las mudanzas por las que, para la época, atravesaba el aparato administrativo en pleno tren de estructuración del Estado nacional brasileño ${ }^{3}$.

Fuera de las elucubraciones que puedan hacerse, lo que es indubitable es que la filiación antiliberal de Silva Monteiro y su defensa de las jerarquías tradicionales coagularon en una de las publicaciones de combate más interesantes que vieron la luz en el contexto de la insurrección farroupilha ${ }^{4}$. Si bien $O$ Mestre Barbeiro tenía los rasgos de la prensa pasquineira que proliferaba en la época (Stolze Lima 57), constituye una rareza hemerográfica por ser la única publicación de la Porto Alegre de aquellos años construida enteramente a base de procedimientos satíricos. La hipérbole; la caricatura verbal, que incluía el uso extendido de apodos caricaturizantes; la parodia de géneros

3 La Revolução Farroupilha (y otras rebeliones provinciales) tuvo lugar en el período regencial, época durante la cual el Imperio fue gobernado por tres regencias sucesivas. Es el lapso comprendido entre la abdicación de d. Pedro I, en 1831, y la declaración de la mayoría de edad del príncipe heredero, d. Pedro II, acontecida en 1840. Marco Morel indica que, en aquellos años, emergieron en Brasil tres partidos: el Exaltado (también llamado farroupilha), el Moderado y el Restaurador (apodado Caramuru). Los restauradores, con lo que vinculamos a Silva Monteiro, constituían una tendencia política de fuerte matiz antiliberal, en la que la soberanía monárquica estaba por encima de la soberanía de la nación o del pueblo. Morel enfatiza, además, la heterogeneidad de elementos agrupados bajo esa tendencia, a su vez que vincula ese sector con el deseo de recomponer el pacto social tradicional, deteriorado por las transformaciones socio-económicas y el proceso de estructuración del Estado brasileño (2003a, 2003b). En 1837, con la renuncia del padre Diogo Feijó a la Regencia y la asunción de Pedro de Araújo Lima, el poder centralizador y represivo del Estado se endurece y se aproximan los moderados y restauradores, conformando lo que se denomina "o Regresso". Pero, al momento en que salió a la luz O Mestre Barbeiro (enero de 1835), aún faltaban dos largos años para la conformación de ese nuevo bloque de poder que difuminaría los límites entre moderados y restauradores.

$4 \quad$ Mención aparte merecería el impresor de la hoja de Silvia Monteiro, el francés Claude Dubreuil, que llegó a Porto Alegre en 1827 para imprimir el primer diario de la ciudad y fundó allí un establecimiento tipográfico que publicó más de una docena de periódicos, entre otras clases de impresos. Los emigrados franceses tuvieron un peso relevante en el desarrollo de las artes gráficas brasileñas, puesto que fueron importantes transmisores de saberes técnicos ligados a la impresión. En parte, ese fue el caso de Dubreuil, aunque su perfil no sea parangonable con el de Pierre Plancher, por ejemplo, comerciante parisino arribado a la corte imperial en 1824, con prestigiosos antecedentes como impresor y librero en la "ciudad Luz". A partir de los pocos rastros que quedaron de nuestro francés, puede deducirse que respondía más al tipo social del aventurero que al del experto en haute typographie. Sobre cultura impresa de Rio Grande do Sul y producción de periódicos en el siglo XIX, véase el detallado trabajo de Rüdiger (1993); sobre Dubreuil en particular, puede consultarse la tesis de Romano (2018). 
consagrados, como manuales, apólogos, tratados de paz, manifiestos, avisos; y la cesión farsesca de la palabra al enemigo eran algunos de los recursos de la sátira que se ponían en juego en la publicación. Respecto de este último, la pequeña hoja portoalegrense presentaba otra particularidad: mientras que en la prensa satírica y gauchesca contemporánea de la región vecina del Río de la Plata la delegación del discurso en clave de farsa se realizaba por espacios acotados (piénsese, por ejemplo, en la carta en verso titulada "La refalosa", aparecida en la gaceta El Gaucho Jacinto Cielo del poeta gauchesco Hilario Ascasubi), en el papel brasileño la voz del adversario acaparaba toda la enunciación dado que la redacción del periódico era atribuida a un barbero liberal, atribución de la que derivaba su título. Este artilugio discursivo tenía por lo menos dos implicancias: en principio, convertía la hoja de Silva Monteiro en un caso extremo de la lógica de alusión del otro que caracteriza a la sátira. Asimismo, le permitía al enunciador real, un monárquico restaurador, inventar una marioneta farroupilha para hacerle decir aquello mismo que la desenmascaraba.

A pesar de que las singularidades que acabamos de mencionar hacen del periódico un interesante objeto de indagación, la hoja de Silva Monteiro fue escasamente trabajada por la historiografía brasileña y nunca fue abordada desde un punto de vista literario ${ }^{5}$. Teniendo en cuenta esto, nuestro propósito es centrarnos en la ventriloquía periodística que articuló el dispositivo de enunciación de la gaceta dado que allí se conjugan dos de los más interesantes aspectos que ofrece la publicación para el análisis literario y discursivo: por un lado, el sutil terrorismo verbal -no por sutil menos agresivo y eficaz-que el enunciador ejercía sobre el lenguaje del otro a quien imaginariamente cedía la palabra; por otro lado, los trazos identitarios -sobre todo los vinculados con componentes raciales- a partir de los cuales ese otro se compuso como un tipo social satirizable. Tales trazos podrían conformar una imagen difusa para un lector actual. Sin embargo, en la coyuntura en que salió el papel, parecen haber delimitado contornos relativamente precisos que activaban

\footnotetext{
Aparece inventariada en las principales historias de la prensa riograndense del siglo XIX (Vianna; Barreto; Silva, Clemente y Barbosa), las cuales aportan sustanciosas informaciones, pero, debido a los propósitos que las guían, no construyen un punto de vista analítico sobre ella. Por su parte, el historiador gaúcho Álvaro Klafke, en su tesis sobre la prensa riograndense del período 1831-1845, se centra en las publicaciones legalistas e incluye en su corpus $O$ Mestre Barbeiro, que analiza desde la perspectiva de la historia política de Rio Grande do Sul.
} 
ciertas representaciones acerca de las mudanzas sociales que atravesaba el Brasil imperial.

\section{EL BARBERO JORNALISTA}

En los años inmediatamente anteriores a la declaración de la independencia de Brasil, el aumento del número de órganos de prensa redundó en la ampliación de la esfera pública más allá de los tradicionales círculos letrados (Neves Bastos 123). Luego de la abdicación de d. Pedro I, ese proceso se intensificó (Barbosa 55; Stolze Lima 57-8). La paulatina incorporación en los debates políticos de las capas intermedias de la sociedad (militares, profesionales, empleados, artesanos) es un dato central del contexto en el que emergió $O$ Mestre Barbeiro, habida cuenta de que en sus páginas se ridiculizaban las aspiraciones de esos sectores. A través de los desatinos de su personaje, Silva Monteiro, acérrimo antiliberal, dejaba entrever que el desborde de la política por fuera de los círculos restringidos de la Corte había hecho que aquella cayera en manos de sujetos que, por su origen, no estaban capacitados para participar de la esfera de poder. ¿Pero por qué el ex escribiente eligió a un barbero para encarnar lo que probablemente a sus oídos fueran las disparatadas ideas del discurso liberal? Según la información aportada por Voyage pittoresque et historique au Brésil (1816-1831) de Jean-Baptiste Debret, los individuos que realizaban las tareas barberiles estaban ubicados en los lugares más bajos de la pirámide social. El pintor francés incluyó en su libro de viajes la litografía de una tienda de barbero, en cuyo texto explicativo aclaraba que en Brasil, a diferencia de lo que ocurría en Portugal, las personas que ejercían ese oficio eran de raza negra (50; ilustración 1$)$.

La naturaleza subalterna del barbero farroupilha se deduce de lo anterior; además -y esto tal vez haya sido lo determinante- los rasgos que componían el personaje creado por Silva Monteiro eran reconocibles en el paisaje de la época como parte de un tipo social que, como tal, era posible de ser satirizado: "Tem aparecido na scena política o Alfaiate, o Sapateiro, o Boticário \&c. e não vi ainda hum snr. Barbeiro; quando este, täobem, ou talvez melhor, que aquelles, podia figurar no seu tanto, sem que a sua ingerencia em política fosse tida como déplacée" $(1,1)$. Este era el dato histórico-político de mayor relevancia que arrojaba $O$ Mestre Barbeiro desde su primera línea, tras lo cual el redactor hacía desfilar por las páginas del periódico los que a sus ojos eran los seres más ínfimos de la sociedad de su tiempo. La catalogación por 
oficio de los advenedizos tornaba palpable lo que Ilmar Rohloff de Mattos denominó el "mundo da desordem": uno de los tres segmentos en los que se dividía, para el historiador, la sociedad del Brasil imperial y que estaba compuesto mayormente por mestizos y esclavos manumitidos. Este universo social se nutría de un sistema basado en la ecuación que igualaba al esclavo/ mercancía con la expectativa de lucro. Así, persiguiendo fines lucrativos, solía enseñárseles a los cautivos distintos oficios (carpintería, costura, albañilería, zapatería) con el objeto de alquilarlos como mano de obra para recuperar la inversión de la compra (Cardoso 83). "Esclavos de ganho" era el nombre con el que se identificaba a los negros que trabajaban fuera de las propiedades de su señor, en medios urbanos principalmente. Muchos de ellos, cuando lograban juntar el peculio necesario, compraban su carta de alforria y, de esa manera, pasaban a engrosar las filas de ese mundo bullente "da desordem" del que habla Rohloff de Mattos.

El oficio de barbero era uno de esos trabajos que ejecutaban los esclavos de ganho o los manumitidos ${ }^{6}$. Si bien todo trabajo manual era absolutamente despreciado en el Brasil esclavista (actitud de la que $O$ Mestre Barbeiro constituye un ejemplo elocuente), sobre la labor barberil pesó, históricamente, un doble tabú dado que, además de cortar el pelo y afeitar, los barberos solían ser sangradores y sacamuelas (de ahí su asimilación con los cirujanos y dentistas, profesiones de las cuales recién se distinguirían acabadamente a fines del siglo XIX). La cercanía con la carne y la sangre sumaba una capa más de desprecio a las que habitualmente se adherían a toda actividad que demandase el uso directo de las manos. No obstante esto, los barberos -y las barberías- tuvieron un papel social destacado en el intercambio de novedades, noticias y chismes. En el primer número del papel de Silva Monteiro se hacía referencia a esa posición que ocupaba el barbero en el tráfico de informaciones, posición que se consideraba irónicamente motivo legitimador de su novel condición de escritor público: "como rapa a todos, tãobem pesca de todos, apanha de todos, colhe de todos, ouve de todos, e como tal está no caso de dizer alguma couza" $(1,1)$. Dentro del juego deformante característico del periódico, esa exposición a la palabra de otros

$6 \quad$ El análisis de los procesos de la Fisicatura-mor (órgano que, entre 1808 y 1828, fue responsable de la reglamentación y fiscalización de las artes de curar) que realizaron Pimenta y Aragão Danta arroja los siguientes datos: entre los pedidos brasileños de autorización para desempeñarse como barberos sangradores, el $84 \%$ correspondía a esclavos y forros. De ese universo, $61.7 \%$ eran cautivos y $38.3 \%$, esclavos manumitidos (8). 
hacía paradójicamente de este barbero una figura monológica. Cierto que su lengua no escapaba de la alteridad discursiva destructora del enunciador real de la gaceta; no obstante, a nivel del enunciado, el personaje no aparecía en situaciones de conversación. En las escenas que lo retrataban, el local del Fígaro brasileño casi siempre estaba desolado, poblado únicamente por su alma y su habla solitaria y delirante.

Mil vezes, tenho deplorado, commigo mesmo, o despreso em que até hoje se acha a arte de barbear (permita-se-me esta phrase, porque agora estou delirando, e me parece que já sou Deputado, Juiz.........! porém, pouco dura a elusão! me está batendo à porta, o preto do Carcereiro, para que o và rapar) porque achando-nos no século da igualdade, não nos consta, que nos bancos da Assambléa, estejão representando os Barbeiros, como estão os Predreiros, Boticarios etc. Finalmente até os quebrados!!!!!! Tornando da Cadêa, continuaremos com este artigo: pelo o que pedimos desculpa, a nossos freguezes, porque já se vé, que não podemos desempenhar a hum mesmo tempo, a penosa tarefa do Redactor do Barbeiro; e se isto nos succede agora ¿que será para a futura Legislatura, que contamos de certo com uma cadeira! $(22,2)$

La escritura del barbero se deslizaba hacia un habla solitaria desplegada "entre as sombras da noite", "com seos botões, com a esteira, e o travesseiro" $(22,2)^{7}$. Semejante a un soliloquio escrito, a un protomonólogo interior que alternaba confusamente el silencio de la escritura y el discurso hablado, la forma de transmisión del pensamiento barberil desautorizaba per se la palabra del personaje, sobre todo si se tiene en cuenta que este defendía los principios ilustrados de la asociación y la filantropía (de hecho, en el número siguiente al que acabamos de citar manifestaría su deseo de fundar una orden filantrópica con sus camaradas de oficio barberil, que sería bautizada, irónicamente, Barbeiros Innatos $)^{8}$. La lengua del barbero, que no encontraba

7 "Falar com seos botões" es una frase idiomática en portugués que significa "hablar solo". El redactor multiplica los objetos inertes a los que se dirige el barbero (la estera y la almohada) y, así, literaliza el modismo lusitano.

En el número 23, el barbero, sumido en sus ensoñaciones, no repara en la llegada de un cliente, quien viéndole en ese estado, lo trata de "louco rematado". Sin sentirse intimidado, el barbero le pregunta: "V.S. já estará [ilegible] com os sublimes principios que emitti no meu N. 22, e como amigo deme hum conselho. ¿Diga-me, com franqueza, os Barbeiros não são de facto, homens mais a propósito, e cahidos como disem do Ceu, para exercer o officio da política antes que os Pedreiros? Portanto, tenho resolvido, inaugurar-me fundador de huma 
cobijo en ninguna escucha, estaba en las antípodas del mecanismo deliberativo que organizaba el discurso de los cuerpos parlamentarios, a la vez que era la forma contraria (y también fronteriza) del diálogo, género muy extendido en la prensa de la época (piénsese en el éxito que alcanzaron los diálogos gauchescos, por ejemplo, en la vecina región rioplatense) y que, en Brasil, siguiendo la tradición del diálogo didáctico humanista y los catecismos cristianos, había constituido una forma privilegiada para la divulgación de conceptos políticos modernos durante la Independencia ${ }^{9}$. No casualmente la voz delirante del barbero era interrumpida por el "preto" del carcelero que lo buscaba para que afeitase a su amo. La discontinuación anotada en el paréntesis adquiría así visos de llamado del "principio de realidad", que de manera sugerente provenía de la prisión, es decir, del sitio que, a los ojos de un restaurador como Silva Monteiro, debía albergar a aquellos advenedizos que no respetaban las jerarquías sociales.

\section{SENTIDOS RACIALES EN O MESTRE BARBEIRO: ENTRE EL DESPRECIO Y EL TEMOR}

La escritura extraviada del periódico, caracterizada por su falta de razón, encajaba con las expectativas derivadas de la identidad racial y socioprofesional de su redactor imaginario. Al lector actual podría resultarle curioso que no haya ninguna indicación explícita acerca de la condición jurídica y étnica del barbero periodista. Seguramente, esto se debía a que se trataba de un dato evidente para los lectores de la época. El mismo carácter tácito de esa información enfatiza su importancia a la hora de dilucidar los sentidos sociales implicados en el papel. Así, la condición de negro y de ex-esclavo

nova Ordem, philantropica, intitulada -Barbeiros Innatos-“ (23, 3). Ante ese parlamento, el cliente se retira sin que el barbero lo note. Por otro lado, en el término "innatos" resuena su contrario "natos" (adjetivo muy usado en la época por los liberales antilusitanos; un brasileiro nato era, en aquel tiempo, un brasileiro patriota). ¿Barbeiros Innatos sería, entonces, una asociación condenada a no nacer y a permanecer en el terreno de las fantasías abortadas del personaje?

Por ejemplo, en octubre de 1821, pocos meses antes de la declaración de la independencia, se publicó en Río de Janeiro una serie de folletos titulados $O$ Alfaiate Constitucional, en los que, a través del diálogo imaginario entre un sastre y sus clientes, se divulgaban nociones relativas al constitucionalismo (Neves Bastos 127). 
asociada a los mestres barbeiros (Debret señala que los barberos que habían alcanzado el grado de mestres eran en general esclavos manumitidos) trazaba un aspecto del imaginario redactor que ponía a la hoja de Silva Monteiro en plena sintonía con los debates que por aquellos años acaparaban el espacio público del Imperio.

En el inicio del período de las regencias, la cuestión de las identidades raciales había cobrado relevancia, en correspondencia con otros dos temas candentes: la discusión sobre la ciudadanía y la nacionalidad. Ivana Stolze Lima explora en los papeles cariocas de los primeros años de la etapa regencial la singular articulación entre prensa, acción política y pertenencia étnica. En un contexto de intensos enfrentamientos políticos que se replicaban en las polémicas entre publicaciones, la historiadora señala la preferencia por los contenidos raciales a la hora de descalificar a los adversarios ${ }^{10}$. En la hoja de Porto Alegre, la elección de un barbero - con la identidad racial a él asociadapara ser el grotesco portavoz de los farroupilhas constituía de por sí un factor de deslegitimación de su discurso; por otra parte, la recurrente tematización, en clave de farsa, de lo que el personaje llamaba "a igualdade dos moleques" ligaba de manera explícita raza y política y apuntaba a la mirada crítica que la gaceta tenía respecto de la subversión de las jerarquías étnicas ${ }^{11}$. En este sentido, la hoja de Silva Monteiro constituía una de las tantas expresiones de la prensa de la época contra las tentativas de ampliación de la ciudadanía. Stolze Lima recoge las críticas volcadas en los papeles públicos contra la excesiva vulgarización de los conceptos políticos liberales, fenómeno que se identificaba con el uso de un lenguaje desmedido "que ocupava as boticas, os armarinhos, os botequins" (63). Los espacios ligados a la sociabilidad popular eran habitados, a los ojos de la elite letrada y dirigente, por "a mais vil canalha aspirante", que aprovechaba los movimientos antimetropolitanos de los sectores dominantes "para colocar em risco as estruturas do regime

10 Además indica que existían múltiples publicaciones cuyos títulos referían a sujetos identificados por su condición étnica (O Brasileiro Pardo, O Crioulinho, O Mulato ou Homen de Cor, O Cabrito).

11 Según el Diccionário de escravidão negra no Brasil de Clóuvis Moura, el término moleque se usaba para referirse a jóvenes negros. Era muy común, por ejemplo, la aparición de la palabra en los avisos de fuga de esclavos y también la empleaba el barbero para referirse a sus aprendices (tenía, decía, "3, ou 4 moleques aprendizes” 28, 1). 
político e social por meio de 'idéias de igualdade, embutidas aos pardos e pretos"” (Rohloff de Mattos 122) ${ }^{12}$.

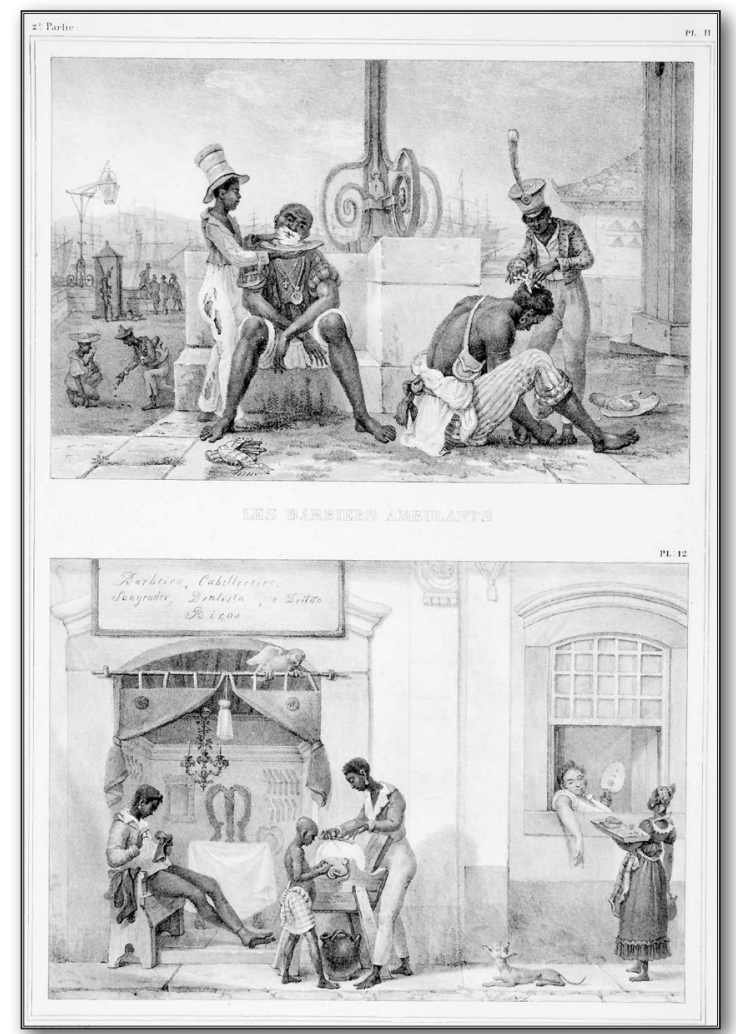

Ilustración 1: barberos ambulantes en las cercanías de la plaza del Palacio (superior) / Barbería carioca (inferior). Fuente: Debret, 1835.

En tanto tipo social, nuestro barbero se identificaba con ese grupo de sujetos cuyas nociones políticas habían sido "embutidas". Su lenguaje contrahecho sería un signo de esa ideologización a la fuerza. Esta imagen peyorativa de la politización de los sectores plebeyos, que en buena medida comulgaba con la sátira corrosiva del papel de Silva Monteiro, tenía como contracara

12 La cita que realiza Rohloff de Mattos en el fragmento transcripto carece de referencia específica. El historiador se limita a decir que se trata de la voz de "uma autoridade". 
el sentimiento de temor que experimentaba "o mundo do governo" respecto de los reclamos de ciudadanía por parte de las clases subalternas. Se trataba de un temor que se tornaba más intenso en los momentos en que los signos del trastrocamiento social y étnico adquirían mayor palpabilidad. En su ensayo "A política nas ruas: os espaços públicos na cidade imperial do Rio de Janeiro", Marco Morel analiza las manifestaciones populares cariocas que ocurrieron en el contexto de la abdicación de d. Pedro I, en las que esclavos o exesclavos se adueñaron de las calles de la ciudad. Aclara que en el período colonial también había turbulencias callejeras, pero que, en el Brasil de la década de 1830, algunas de ellas "passam a ter também uma conotação ligada à cidadania" (67).

Eram clamores que despertavam temores. Os gritos e vozes nas ruas constituem, aliás, uma forma de ocupação dos espaços públicos, ainda que simbólica e efémera, mas muitas veces eficaz e impresionante. É o que se chama de "Voz Popular", tantas vezes referida em fontes documentais dos séculos XVIII e XIX (A política 66).

Esa "voz popular" no escapó al testimonio que de aquel tiempo convulsionado hizo Silva Monteiro en su hoja periódica. "A Molequiada", poema publicado en el número 28 de su papel, recogía modos de la voz que se acercaban a los clamores callejeros descriptos por Morel. La pieza es una cuarteta de pentasílabos con rima consonante en los versos pares, forma de arte menor ligada a la tradición de la poesía popular. La división estrófica no está marcada, pero el poema está dividido en tres conjuntos de versos (cada uno de cuatro cuartetas). "Cantar pertendo / Do Moleque Nato. / Sem Lyra de ouro / Nem patronato" $(28,4)$, dice la primera cuarteta. El adjetivo "nato" solía combinarse en la época con "brasileiro" ${ }^{13}$. Un "brasileiro nato" era una de

13 En muchos países esclavistas, los procesos de abolición fueron graduales. La institución del patronato ofició de transición entre la esclavitud y la libertad. Suponía la reformulación jurídica de la relación entre amos y cautivos: el propietario devenía "patrono" y el esclavo, "patrocinado". El primero tenía la obligación de mantener y brindar educación al segundo (en caso de que fuese joven) y también el derecho de utilizar su trabajo pero a cambio de retribuirlo con un salario. En Brasil, no existió la institución del patronato. Sí en el Río de la Plata, donde se estatuyó con la declaración de la libertad de vientres en 1813 (en la América lusa, una ley semejante recién se promulgaría en 1871). La imagen de los jóvenes negros "sem patronato" que aparece en "A Molequiada" aludía a una libertad "desmedida", que se condice con la función de control sobre la población negra que buscaba ejercer la figura jurídica del patrono. 
las maneras en las que se autodenominaban los liberales exaltados, en tanto se asumían como patriotas defensores de la independencia de Brasil frente a las pretensiones lusas. El sintagma "Moleque Nato" suponía, entonces, una distorsión del vocabulario político de aquel tiempo. Vaciaba de sentido la fórmula liberal, pero también revelaba la articulación que analiza Stolze Lima entre identidad racial, nacionalidad y ciudadanía, así como el acercamiento de los sectores sociales relegados a los liberales exaltados.

Las dos primeras series de estrofas de la composición no solo "reivindicaban" los "Patrios Direitos" de los moleques, sino que también configuraban el ámbito de despliegue de una poesía humilde, que no contaba con las prerrogativas de una "Lyra de ouro" y que, según se lamentaba el yo poético, había sido largamente olvidada por "as nove Muzas / Lá do Parnas". El barbero ejercitaba esa modalidad literaria, oral y popular, acompañado de un rústico instrumento, un "oco Cabaço" con "cordas de Embira", que recuerda al cavaquinho portugués ${ }^{14}$. Pero así como se asociaba al barbero con el canto, a los jóvenes negros cuyos derechos este defendía se los vinculaba con un universo acústico ubicado más allá de la poesía:

Vivas, e morras

São os deleites

São regocijos,

São precedentes:

Desses Moleques

Que a qualquer hora,

Não se embaração

De Gritar; fora.

Com pega, mata,

Rompe vidraças,

Se aterrão velhos,

Mulheres crianças;

Com algazarras

E espalhafatos

Se ganha a fama

De Patriota Nato. $(28,4)$

\footnotetext{
Es un instrumento de cuatro cuerdas, muy semejante a la guitarra pero de un tamaño bastante menor. Fue introducido en Brasil por los conquistadores portugueses. Generalmente se lo utiliza rasgándolo con los dedos para acompañar la voz. Se construye con diferentes maderas. Hay cavaquinhos hechos con calabazas secas y ahuecadas.
} 
El poema les atribuía a los moleques, más que una voz, un tumulto sonoro, alusivo de un escenario de desmanes callejeros, que desbordaba la pretendida racionalidad del régimen político y social imperante para configurar una escena de(1) terror. Esta última serie de cuadras componía la imagen del "monstruo sin rostro" de la muchedumbre, que solo atinaba a representarse en un registro auditivo, y que encarnaba en las elites el temor de la disolución social producto de los desenfrenos de la soberanía del pueblo (Rosanvallon 61).

Así, la composición sacaba al lector del ámbito de la barbería para empujarlo a la calle. Dibujaba el tránsito entre el espacio de las disparatadas ensoñaciones políticas barberiles a otro en que aquellas se traducían en un accionar violento y en modalidades de la voz que se correspondían con la intensidad de ese accionar. El movimiento era el exacto reverso del pasaje del barbero por la prisión, cuando fue requerido por el carcelero para que le cortase la barba. Si ese episodio se distinguía en la trama del periódico por su racionalidad, puesto que el llamado hacía que el barbero volviese a la razón, "A Molequiada" trazaba el camino descendente hacia la sinrazón, la extinción de la voz de los negros, rasgo paradigmáticamente humano; el devenir de sus voces en gritos ("vivas e morras"), ruido de vidrios rotos, algazaras, barullo y desorden (sentidos que condensa el vocablo portugués espalhafatos). La distorsión que supone el pasaje del sonido musical del instrumento del barbero al barullo ensordecedor de la manifestación trazaba la línea que culminaba en la deshumanización de los moleques, quienes eran representados fuera del campo de los sonidos articulados de la lengua.

\section{LA ESCRITURA DEL BARBEIRO O LA ARTESANÍA AL REVÉS}

Déplacée ("fuera de lugar") es el término con el que Silva Monteiro eligió ironizar, en las primeras líneas de su periódico, sobre el desacomodo que experimentaba en aquellos años el ordenamiento tradicional de la sociedad brasileña (recuérdese esta frase de la primera cita que hicimos del periódico en el apartado anterior: "sem que a sua ingerencia [la del barbero] em política fosse tida como déplacée"). La intromisión de un término en francés, práctica que se repetiría en los siguientes números, quebraba desde el principio la unidad lingüística e ideológica del discurso barberil. Poco convincente resultaba que un barbero escribiese en la lengua de Molière. Además, que el énfasis recayera justamente sobre el adjetivo déplacée (del verbo déplacer, que significa "desplazar") no era casualidad. Se trataba de indicar a los lectores 
desde la primera frase cuál era el enjuiciamiento adecuado que debía hacerse respecto de sujetos que escalaban posiciones en la pirámide social y que, sin las tradicionales credenciales nobilitantes, disputaban lugares de poder.

Pero, además, leído en retrospectiva, el vocablo extranjero se carga de refulgencias semánticas que enlazan pasado y futuro como si de su materialidad emergieran capas de sentido que solo con el tiempo hubieran explotado su potencialidad. ¿No hay allí un núcleo significativo de la experiencia del advenimiento de la era moderna (política, económica, social) en el Brasil imperial? La manera en la que Silva Monteiro se mofaba del barbero (insistimos en su condición de esclavo manumitido) ilumina una de las contradicciones centrales del liberalismo brasileño decimonónico, que surgía por la tensión entre el principio liberal de igualdad que caracterizaba a esa ideología y la manera restrictiva en que tal principio era asumido en Brasil, en un contexto social en el que imperaba un régimen de producción esclavista. Desde este punto de vista, O Mestre Barbeiro testimoniaría a su manera el desequilibrio de la vida ideológica del Brasil decimonónico que analizó Roberto Schwarz en su ensayo "As idéias fora do lugar" (1973). Nótese la equivalencia semántica que puede trazarse entre el "fora de lugar" que Schwarz eligió para expresar el desajuste de la realidad brasileña y la palabra francesa déplacé. Desde ese punto de vista, puestas en boca de un esclavo o exesclavo, las ideas liberales no hacían más que erosionar su pertinencia en un país en el que el liberalismo solo se ejercía en un plano económico, sin un correlato de libertad social y política. Por ese hiato que se dibujaba entre los enunciados de carácter progresista y la realidad jurídica de su sujeto de enunciación se derramaban todos los contrasentidos que impregnaban las páginas de $O$ Mestre Barbeiro. El dispositivo escriturario que hábilmente construyó Silva Monteiro encontraba su matriz en esa dislocación ${ }^{15}$.

15 El ensayo de Schwarz fue revisitado en diversas oportunidades y su concepto central fue criticado y reelaborado. Palti, en "Lugares y no lugares de las ideas en América Latina" pasa revista de las principales relecturas de las que fue objeto la noción de "fuera de lugar" (Carvalho Franco y Santiago) y propone una reversión basada en una concepción de lenguaje no referencialista, que tiene en cuenta factores pragmáticos de la enunciación. Para el historiador argetino, "los desequilibrios no remiten, en este contexto, a la relación entre 'ideas' y 'realidades' - concepto que tiene siempre implícito (al menos como contrafáctico) el ideal de una sociedad completamente orgánica, en la que 'ideas' y 'realidades' converjan-, sino a las de las ideas respecto de sí mismas. Y este tipo de dislocaciones resultan, en efecto, inevitables. Éstas derivan, como vimos, de la coexistencia y superposición, en un mismo sistema, de códigos heterogéneos entre sí" (2007: 302). En definitiva, la alteridad de las ideas 
En el plano interno de la composición de la hoja periódica, la ironía como tropo organizador de la escritura hacía que aquello que se quería dar a entender estuviese ausente de las páginas del periódico. Por lo tanto, la palabra "déplacé", cuyo origen extranjero la hacía fácilmente separable del sentido literal que adquiría dentro de la frase en la que estaba emplazada, constituía un alerta a los lectores, la marca inicial de una serie de múltiples señales que desplegaría el periódico y que funcionarían como un protocolo de lectura brindando referencias explícitas de la manera en la que había que leer la publicación. Desde esta óptica, el hacer escriturario de Silva Monteiro era subrepticio, dado que construía sentido de una manera sutil, a través del deslizamiento de frases, signos de puntuación, voces extranjeras, letras, cursivas, que distorsionaban, con un tenue cambio en la materia, el discurso del barbero. La alteración mínima del nombre de los enemigos a través de un simple guión, esto es, la escritura farrou-pilhas ("pilhas" significa en portugués "ladrones"), diseñaba, por ejemplo, un calambur, que inscribía en la superficie del texto una injuria contra los liberales (el procedimiento iba, en realidad, más lejos: su eficacia radicaba en que, una vez develado el juego de palabras, el barbero no podía proclamar su filiación política sin proferir a la vez un auto-agravio). La transcripción equívoca del oficio de un "patriota" (así se identificaban a sí mismos los farroupilhas) en el que se leía "inderessado" en vez de "endereçado" (dirigido, enviado) ponía en tela de juicio la imparcialidad del contenido del escrito dirigido a un juez de paz. De esa manera se carcomía la homogeneidad del discurso liberal que encontraba en el barbero su portavoz. Los pequeños signos distribuidos aquí y allá mostraban los dobleces semánticos en lo que se abrumaba el universo ideológico antagonista.

En El grado cero de la escritura, Barthes ofrece una metáfora que permite enlazar la práctica de la escritura literaria con el trabajo artesanal. Sostiene que, hacia mediados del siglo XIX, comienza a elaborarse en Francia "una imaginería del escritor-artesano que se encierra en un lugar legendario, como

depende de la dimensión política en la que tiene lugar la contienda entre esos códigos diversos y sus también divergentes protocolos de lectura. A propósito de esto último, cabe mencionar el análisis que propone Alfredo Bosi (1988) del liberalismo brasileño, que toma distancia de las interpretaciones "abstractas" del concepto para proponer una interpretación contextual que dé cuenta de la selectiva lectura que la elite del ochocientos realizó de la ideología europea. Sobre liberalismo en Brasil y su conjunción con el sistema esclavista, además del ensayo de Bosi, véanse los trabajos de Nogueira 1984; Malerba 1994 y Santos 1998. 
el obrero en el taller, y desbasta, pule, talla y engarza su forma”. Agrega que, incluso, se crea "un preciosismo de la concisión (trabajar una materia en general es cortar parte de ella), opuesto a cierto preciosismo barroco (el de Corneille por ejemplo)" (El grado cero 66-67). Si bien es relativa a un lugar distante de la Porto Alegre de la década de 1830, la figura del escritor-artesano se ajusta en alguna medida a Silva Monteiro dado el trabajo delicado que emprendió para corroer la materia en la que se encarnaba el ideario enemigo. El estilo de escritura de su hoja se identificaba con el carácter filoso del instrumental barberil. Como si él también estuviese munido de tijeras y navajas, Silva Monteiro cortaba para sacar de contexto, amputaba y rasuraba para hacer lugar a una palabra que carcomía los sentidos del discurso contrario. Así, el cuerpo y la lengua se amalgamaban metafóricamente en una práctica escrituraria de impronta manual, en la que el oficio de escribiente y secretario del escritor se revela como uno de los trazos más elocuentes de su biografía.

Se trataba de un "manoseo" de la palabra liberal que amplificaba la equivocidad del lenguaje. "Na verdade, mandar prender a hum pronunciado por crime de sedição, cuja pena não passa de 3 a 12 anos de prisão com trabalho, segundo o art. 111 do Codigo Criminal, he =hum caso nunca visto=!! Mandar recolher à Cadeia hum criminoso, he sem duvida alguma enxovalhar muito a Provincia de Rio Grande!!” (1) rezaba un artículo aparecido en el número 18. En él, se citaba un texto del ya mencionado Recopilador Liberal, que denunciaba la prisión ilegal de uno de los líderes farroupilhas de la provincia, José Mariano de Mattos. Pero O Mestre Barbeiro no se limitaba a citar, sino que intercalaba entre la palabra del periódico enemigo una referencia al Código do Processo del Imperio. Con la intromisión de la ley imperial, el papel de Silva Monteiro ponía en evidencia, a contrapelo de la hoja farroupilha, que el sargento Mattos había cometido un delito para el que el Código preveía una pena de prisión nada insignificante. El énfasis puesto en $=$ hum caso nunca visto=, que constituía una cita directa del texto de $O$ Recopilador, disparaba dos lecturas posibles. O subrayaba la insensatez de la publicación y del barbero, apuntalada con la frase contigua ("Mandar recolher à Cadeia hum criminoso [...]"); o constituía un caso de apropiación invertida de la palabra ajena: mientras que, para el Recopilador, el encarcelamiento de Mattos configuraba un estado de excepción repudiable, que atentaba contra las garantías individuales de los ciudadanos, para Silva Monteiro, se trataba de una feliz excepción, que, en realidad, debía constituir la regla (la excepcionalidad del caso derivaba de un contexto de incumplimiento generalizado de las leyes que, para el escritor, era lo verdaderamente impugnable). 
Ahora bien, dijimos que el perfil de Silva Monteiro solo en alguna medida se asemejaba al del escritor-artesano. Desde el punto de vista del producto terminado, el tipo de labor desarrollada por el exescribiente de Porto Alegre estaba en las antípodas de todo preciosismo artesanal, y esto porque la finalidad de las intervenciones que realizaba no era dar forma a la lengua del barbero, sino precisamente de-formarla. La trayectoria deformante que la escritura recorría en la publicación brasileña se puede seguir y reseguir de una manera gráfica recurriendo otra vez a Barthes, específicamente, a la lectura que propone sobre la iconografía de la Enciclopedia. Los philosophes que participaron de esta inmensa obra catalogaron con un precioso detallismo los objetos tecnológicos de su época. Ese detallismo se desplegaba en un nivel verbal y en un nivel iconográfico. En relación con este último, que es el que Barthes analiza, cada una de las entradas estaba acompañada de láminas con dibujos que, en su parte superior, mostraban una escena donde el objeto a definir se representaba sintéticamente (por ejemplo, en la entrada Barberie, se muestra el interior de una barbería con varios barberos usando sus herramientas habituales; ilustración 2), mientras que, en la parte inferior, el elemento era sometido a una representación analítica que desmembraba cada uno de sus componentes (siguiendo con el ejemplo de la barbería, en este sector de la lámina se representan todas las herramientas del barbero, que llegan a un número de 30 . Ilustraciones 2, 3 y 4). Barthes señala que las ilustraciones emplazadas en la parte superior mostraban el trayecto que iba de la materia en bruto al objeto terminado y realizaban, así, la "epopeya de la materia", que no es otra cosa que "el encaminarse de la razón" (Las láminas 137); por el contrario, en las imágenes inferiores, en las que el objeto aparecía diseccionado y -por efecto mismo de esa disección-irreconocible, se alojaba lo monstruoso, que componía un lenguaje iconográfico contraracional (Las láminas 142). "En su orden mismo, la lámina enciclopédica realiza ese peligro de la razón", explica Barthes, que se constituye a partir de la propia deriva paroxística del pensamiento analítico (Las láminas 145).

Los experimentos polifónicos que realizaba $O$ Mestre Barbeiro con la palabra del adversario se asemejan al trabajo de representación del que fueron producto las escenas descompuestas en extraños objetos que aparecen en las láminas inferiores de la Enciclopedia. El discurso liberal que Silva Monteiro encarnaba en la voz de un humilde oficial mecánico y que sometía al filo de las navajas y tijeras (que producían alteraciones, borraduras, correcciones, agregados volviendo su sentido equívoco) trazaba un camino zigzagueante hacia la sinrazón, durante el cual se exhibía la tragedia de una materia (lingüística e ideológica) sujeta a los azares del aniquilamiento. Barthes asocia 
la figuración monstruosa del objeto enciclopédico con el discurso poético, debido al trabajo minúsculo con la forma que ambos suponen. La escritura que practicó Silva Monteiro suponía una delectación respecto de la materialidad de la lengua (en relación con la cual se puede pensar en parentesco con las textualidades poéticas), una labor artesanal sobre las palabras para liberar de ellas sentidos secretos que socavaban las certezas del discurso contrincante.

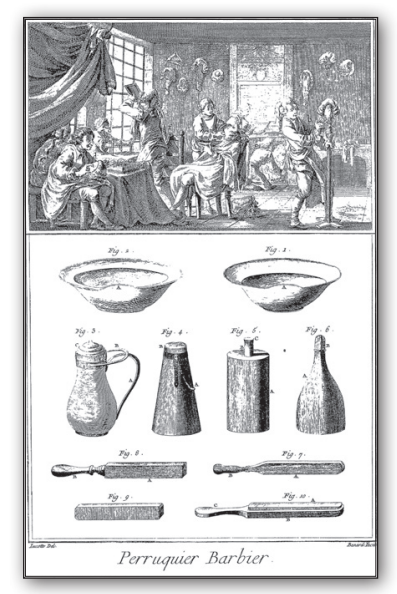

Ilustración 2: barbería (superior) / utensilios de barbero (inferior).

Fuente: Diderot y D'Alembert, 1751-1755.
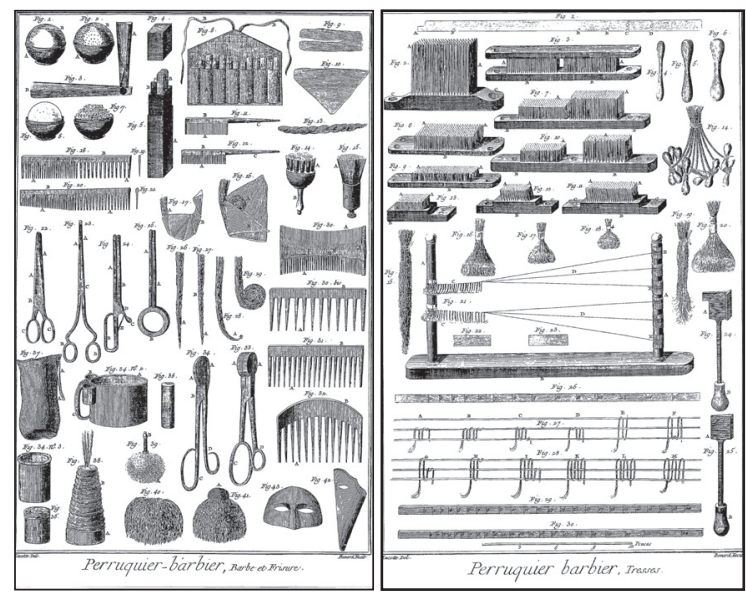

Ilustración 3: utensilios de barbero / Ilustración 4:

utensilios de barbero. Fuente: Diderot y D'Alembert, 1751-1755. 


\section{PARA CONCLUIR: UN TUMULTO DE PALABRAS}

En la ficción de escritura que el periódico de Silva Monteiro daba a leer, se cifraban las alteraciones del orden jerárquico de la sociedad tradicional brasileña, alteraciones que el escritor caramuru quería combatir y denunciar. El hecho de que un mestre barbeiro, con las presunciones raciales y jurídicas que el ejercicio de dicho oficio convocaba, asumiera la escritura de un periódico era un signo elocuente del proceso de redistribución de la palabra pública. La prensa, en tanto nuevo dispositivo escriturario que se extendió en Brasil sobre todo luego de la Independencia, favoreció esa redistribución, dado que se convirtió en la arena privilegiada de despliegue de las reivindicaciones ciudadanas de los grupos sociales medios y bajos que reclamaban su derecho a la participación política. Por ello, la imagen que de ella construyó la elite es la de una prensa exaltada e instigadora de tumultos contra el poder establecido (Stolze Lima 57).

Desplazar, dislocar, deslizar. Esas eran las palabras de des-orden usadas para representar, en la hoja de Silva Monteiro, los peligros de la época. Podríamos decir que cuando la escritura del barbero se deslizaba más allá de los límites imprecisos que la contenían se producía la deflagración. Como sucedía en el episodio de ensoñación que comentamos en el primer apartado: el artículo que estaba escribiendo el barbero se confundía con un monólogo delirante y en voz alta "com seos botões, com a esteira, e o travesseiro", cuyo desarrollo era frenado cuando entraba en la escena el esclavo del carcelero. La prisión aparecía como el espacio social que podía contener la proliferación de las voces peligrosas. En efecto, ese era el tipo de despliegue oral que más se temía, como permite vislumbrar también el poema "A molequiada": la voz "lírica" del barbero resbalaba, caía y se confundía con la gritería de la turba de moleques que asolaban las calles de una ciudad que, por lo menos por un rato, parecía pertenecerles. El poema construía, así, un umbral de encuentro entre la poesía popular y las voces del pueblo desplegadas en momentos de turbulencias sociales. Registrando el fugaz universo sonoro de los clamores de las muchedumbres, la composición establecía un terreno identificable con formas vocales disímiles -la canción de guerra y la canción política, las consignas, los lemas de creación espontánea y los vítores- pero que tienen la característica común de acompañar la acción.

En El momento Guizot, Rosanvallon se refiere al "espectro" que acosaba a la mayor parte de los publicistas de comienzos del siglo XIX: "Visión de la masa revolucionaria incontrolable, de la masa indistinta e imprevisible, 
monstruo sin rostro y sin límites, básicamente irrepresentable por ser el grado cero de la organicidad" (62). Desde una ciudad doblemente periférica, $O$ Mestre Barbeiro tuvo el mérito de construir una representación de ese conjunto amorfo e irrepresentable. Pero la visión de la masa devino, en sus páginas, en imagen verbal o, mejor, en palabra en acto. La manera en la que Silva Monteiro procedió con el lenguaje del adversario hizo de este una expresión tumultuaria, pero no porque incentivara al tumulto, sino porque ese fue el mecanismo elegido para (des)componer el cuerpo discursivo enemigo. El exescribiente se apropiaba de los que arriba llamamos palabras de des-orden y dislocaba la lengua liberal, deslizaba sobre ella elementos que la vaciaban de sentido como una manera de anarquizarla. En términos literarios, resulta muy interesante que muchos textos del Barbeiro se presentaran como un magma informe de trozos de "pensamiento" (de ahí que hayamos hablado de protomonólogo interior), un torrente indeterminado que estaba en las antípodas de las ideas claras y distintas por las que clamaba el racionalismo de tinte cartesiano. Es que la intención de construir una representación satirizada de un sujeto plebeyo derivó en una figuración de su mundo interior bastante singular, cuya ilogicidad, inconexión, cualidad digresiva, fragmentaria y proliferante recuerda procedimientos literarios que aparecerían varias décadas más tarde. No estaría mal recordar, en este punto, que justamente el mestre barbeiro se ocupaba de las cabezas de sus clientes, él, cuya cabeza se dilataba en el sinfín de cortes, borrones y agregados con los que se representaba su abigarrado devaneo interior. En una sociedad en la que el trabajo manual se menospreciaba y era realizado exclusivamente por cautivos, la cabeza trepidante y bullente del barbero constituía de por sí una paradoja. Le pertenecía a un sujeto cuya condición social tenía un efecto sinecdóquico sobre su persona porque lo reducía a la fuerza y habilidad de sus manos. Una cabeza sobre el cuerpo equivocado (o al revés): dislocación máxima y fundante, entonces, que daba cuerda al complejo mecanismo de enunciación que singulariza $O$ Mestre Barbeiro.

\section{BIBLIOGRAFÍA}

Alves, Francisco das Neves. Revolução Farroupilha: estudos históricos. Rio Grande: Fundação Universidade Federal do Rio Grande, 2004.

Barbosa, Marialva. História cultural da imprensa. Brasil 1800-1900. Río de Janeiro: Mauad $\mathrm{X}, 2010$. 
Barthes, Roland. El grado cero de la escritura seguido de nuevos ensayos críticos. Buenos Aires: Siglo XXI, 2003.

"Las láminas de la Enciclopedia". El grado cero de la escritura seguido de nuevos ensayos críticos. Buenos Aires: Siglo XXI, 2003. 123-147.

Barreto, Abeillard. Primórdios da Imprensa no Rio Grande do Sul. Porto Alegre: Comissão Executiva do Sesquicentenário da Revolução Farroupilha, 1986.

Bosi, Alfredo. “A Escravidão entre dois Liberalismos”. Estudos Avançados 3.2 (1988): 4-39.

Cardoso, Fernando Henrique. Capitalismo e escravidão no Brasil meridional. O negro na sociedade escravocrata do Rio Grande do Sul. Río de Janeiro: Civilização brasileira, 2003.

Debret, Jean-Baptiste. Voyage pittoresque et historique au Brésil ou séjour d'un artiste français au Brésil (1816-1831), tomo II. París: Firmin Didot Freres, 1835.

Diderot, Denis y Jean Le Rond D'Alambert, dirs. Encyclopédie, ou Dictionnaire raisonnée des sciences, des arts et des métiers. 1751-1755. Septiembre 2018. http://encyclopédie. eu/index.php

Fernandes de Mello, Tancredo. "Os primeiros jornais do Rio Grande do Sul”. Almanaque Popular Brasileiro para o ano 1905. Pelotas: Echenique, Irmãos \& Cia. - Livraria Universal, 1904.

Flores, Moacyr. Revolução Farroupilha. Porto Alegre: Martins Livreiro-Editor, 1985.

Gutfreind, Ieda. A historiografia rio-grandense. Porto Alegre: Ed. UFRGS, 1992.

Klafke, Álvaro Antonio. “Antecipar essa idade de paz, esse império do bem. Imprensa periódica e discurso de construção de Estado unificado (São Pedro do Rio Grande do Sul, 18311845)". Tesis doctoral. Universidade Federal do Rio Grande do Sul, 2011.

Kühn, Fábio. Breve história do Rio Grande do Sul. Porto Alegre: Leitura XXI, 2002.

Malerba, Jurandir. Os brancos da lei: liberalismo, escravidão e mentalidade patriarcal no Império do Brasil. Río de Janeiro: EDUEM, 1994.

Morel, Marco. "A política nas ruas: os espaços públicos na cidade imperial do Rio de Janeiro". Estudos Ibero-Americanos XXIV. 1 (1998): 59-73.

"Restaurar, fracionar e regenerar a nação: o Partido Caramuru nos anos 1830". Brasil: formação do Estado e da nação. Coord. István Jancsó. San Pablo: HUCITEC, 2003a. 407-430.

O período das Regências (1831-1840). Río de Janeiro: Jorge Zahar, 2003 b.

Moura, Clóvis. Dicionário de escravidão negra no Brasil. San Pablo: EDUSP, 2004.

Nedel, Letícia Borges. "Regionalismo, historiografia e memória: Sepé Tiaraju em dois tempos". Anos 90 11. 19/20 (2004): 347-389.

"Um passado novo para uma história em crise: regionalismo e folcloristas no Rio Grande do Sul”. Tesis doctoral. Universidade de Brasília, 2005.

Neves Bastos P., Lúcia. "Leitura e leitores no Brasil, 1820-1822: o esboço frustrado de uma esfera pública de poder". Acervo 8.1-2 (1995): 123-138.

Nogueira, Marco Aurélio. As desventuras do liberalismo: Joaquim Nabuco, a Monarquia e a República. Río de Janeiro: Paz \& Terra, 1984.

Palti, Elías. El tiempo de la política. El siglo XIX reconsiderado. Buenos Aires: Siglo XXI, 2007. 
Pesavento, Sandra. A Revolução Farroupilha. San Pablo: Brasiliense, 1985.

Rohloff de Mattos, Ilmar. O tempo saquarema. San Pablo: HUCITEC, 1987.

Romano, María Laura. "Monstruos de la razón. Periódicos no ilustrados en la región platina (1820-1830)". Tesis doctoral. Universidad de Buenos Aires. 2018.

Rosanvallon, Pierre. El momento Guizot. El liberalismo doctrinario entre la Restauración y la Revolución de 1848. Buenos Aires: Biblos, 2015.

Rüdiger, Francisco. Tendências do jornalismo. Porto Alegre: Ed. Da UFRGS, 1993.

Ruedas, Manuel. O Recopilador Liberal. Porto Alegre: Typ. de V. F. Andrade, 1832-1836.

Salgado Pimenta Tania y Rodrigo Aragão Dantas. "Barbeiros-sangradores no Rio de Janeiro oitentista: transformações de um ofício". Revista da Associação Brasileira de Pesquisadores Negros 6.14 (2014): 6-24.

Santos, Wanderley Guilherme dos. Décadas de Espanto e uma Apologia Democrática. Río de Janeiro: Rocco, 1998.

Schwarz, Roberto [1973]. “As idéias fora do lugar”. Ao vencedor as batatas. Forma literária e processo social no início do romance brasileiro. San Pablo: Duas Cidades Editora, 2000. 9-31.

Silva, Jandira et al. Breve histórico da imprensa sul-rio-grandese. Porto Alegre: CORAG, 1986.

Silva Monteiro, José da. O Mestre Barbeiro. Porto Alegre: Typ. de C. Dubreuil \& Comp., 1835.

Stolze Lima, Ivana. "Pasquins e cidadania no período regencial". Imprensa, história e literatura. Dir. Isabel Lustosa. Río de Janeiro: Edições Casa de Rui Barbosa, 2008. 57-74.

Vianna, Lourival. Imprensa gaúcha (1827-1852). Porto Alegre: Museu de Comunicação Social Hipólito José da Costa, 1977. 